\title{
Heptadecanoic acid inhibits cell proliferation in PC-9 non-small-cell lung cancer cells with acquired gefitinib resistance
}

\author{
CHANGZHI XU ${ }^{1 *}$, PENGFEI WU ${ }^{1 *}$, JIAJIA GAO $^{1}$, LANLAN ZHANG $^{1}$, TENGFEI MA $^{2}$, \\ BINGBING MA ${ }^{2}$, SHUAI YANG ${ }^{3}$, GUOJIAN SHAO ${ }^{3}$, YANG YU ${ }^{3}$, XUNDUAN HUANG $^{3}$, \\ XINGYUAN YANG ${ }^{1}$ and BUCHANG ZHANG ${ }^{1}$ \\ ${ }^{1}$ Institutes of Physical Science and Information Technology, ${ }^{2}$ Biotechnical Research Centre for Anhui Tianxiang Cereals, \\ Oils and Foodstuffs Co., Ltd., ${ }^{3}$ School of Life Sciences, Anhui University, Hefei, Anhui 230601, P.R. China
}

Received December 3, 2018; Accepted April 15, 2019

DOI: $10.3892 / o r .2019 .7130$

\begin{abstract}
Non-small cell lung carcinomas (NSCLC) are common and are the leading cause of cancer-associated mortality worldwide. Heptadecanoic acid (C17:0) is an odd-chain saturated fatty acid. The effect of $\mathrm{C} 17: 0$ on lung cancer has remained elusive. The present study examined the role of C17:0 in the PC-9 NSCLC cell line and PC-9 cells with acquired-gefitinib resistance (PC-9/GR) in vitro. Cell proliferation, migration, apoptosis, fatty acid composition and the activation of relevant signaling pathways were assessed. The results indicated that C17:0 significantly inhibited cell proliferation, and migration, while promoting apoptosis in PC-9 and PC-9/GR cells. Furthermore, C17:0 enhanced the cytotoxicity of gefitinib to PC-9 and PC-9/GR cells. Mechanistical analysis indicated that the activation of the phosphoinositide 3-kinase/Akt signaling pathway was suppressed in C17:0-treated PC-9 and PC-9/GR cells. Furthermore, the addition of C17:0 led to accumulation of 10-cis-heptadecenoic acid in NSCLC cells. Collectively, the present study demonstrated that $\mathrm{C} 17: 0$ is an effective agent against NSCLC cells in vitro and the results may imply that the intake of $\mathrm{C} 17: 1$ or C17:0-rich food may be beneficial during the treatment of NSCLC.
\end{abstract}

\section{Introduction}

Non-small cell lung cancer (NSCLC) accounts for the majority of lung cancers, and is the leading cause of cancer-associated mortality worldwide (1). In NSCLC, the human epidermal growth factor receptor (EGFR) is commonly amplified or

Correspondence to: Professor Buchang Zhang, Institutes of Physical Science and Information Technology, Anhui University, Qingyuan Campus, 111 Jiulong Road, Hefei, Anhui 230601, P.R. China

E-mail: zhbc@ahu.edu.cn

*Contributed equally

Key words: heptadecanoic acid, NSCLC, gefitinib, acquired resistance mutated, leading to constitutive activation of downstream signaling pathways, including phosphoinositide 3-kinase (PI3K)/Akt and extracellular signal-activated kinase signaling pathways. Furthermore EGFR mutation is frequently encountered in women and non-smokers in East Asia with NSCLC (2). The application of EGFR tyrosine kinase inhibitors (TKIs), including gefitinib, has marked efficacy with higher response rates and longer progression-free survival $(3,4)$. However, patients with NSCLC who initially respond to EGFR-TKIs often acquire resistance due to the secondary mutations of EGFR, including T790M (5). Gene mutations may be accelerated by environmental factors, including smoking, air pollution and lifestyle. Environmental factors are as important as genetic factors in provoking tumor occurrence and development. Recently nutritional therapy has drawn increasing attention in cancer treatment. Certain nutrients have been demonstrated to be correlated with the progression of various diseases. For instance, asparagine has been demonstrated to stimulate metastasis in a model of breast cancer (6). Dietary fat has been demonstrated to promote prostate cancer development, suggesting that inhibition of fatty acid synthase may be useful for controlling prostate cancer $(7,8)$. Hence, screening of functional dietary nutrients may provide an approach for controlling lung cancer development and resistance to therapies, including chemotherapy.

Heptadecanoic acid $\left(\mathrm{CH}_{3}\left(\mathrm{CH}_{2}\right)_{15} \mathrm{COOH} ; \mathrm{C} 17: 0\right)$, also known as margaric acid, is an odd-chain saturated fatty acid (OCS-FA). It exists in animal fat at a small concentration (1-5\%), while it hardly occurs in natural vegetable lipids. With the development of analytical techniques, OCS-FAs were identified to be rich in ruminant fats and fish oils. OCS-FAs are present at insignificant plasma concentrations ranging from 0 to $1 \%$ in human bodies. $\mathrm{C} 17: 0$ and pentadecanoic acid $\left(\mathrm{CH}_{3}\left(\mathrm{CH}_{2}\right)_{13} \mathrm{COOH}\right.$; $\left.\mathrm{C} 15: 0\right)$ are commonly used as low cost internal standards in quantitative analysis. Studies have indicated that C15:0 and C17:0 are associated with health and several diseases, including the incidence of coronary heart disease (9), prediabetes and type 2 diabetes (10) as well as multiple sclerosis (11). In addition, the tissue levels of OCS-FAs were identified to be lower in Alzheimer's disease compared with those in a control group (12). Certain studies have indicated that odd branched-chain fatty acid (OBCFA) 
possesses a marked anti-tumor activity $(13,14)$. Similarly, C17:0 has been reported to be effective against lymphoma cells (15). However, the efficacy of C17:0 against lung cancer cells and gefitinib-resistant NSCLC cells has remained elusive. Studies on the association between OCS-FAs and cancer would reveal more comprehensive functions of OCS-FAs and provide a potential application of health nutritional therapy in lung cancer prevention and treatment.

In the present study, the PC-9 NSCLC cell line and PC-9 cells with acquired-gefitinib resistance (PC-9/GR) were used. The effect of C17:0 on NSCLC was compared with that of other dietary fatty acids contained in animal oils. In the experiments, C17:0 was identified to be effective against PC-9 and PC-9/GR cells. Furthermore, the effects of C17:0 on cell migration and apoptosis, as well as alterations in the fatty acid composition and associated signaling pathways were assessed.

\section{Materials and methods}

Cell culture. A normal human bronchial epithelioid (HBE) cell line was purchased from the Cell Bank of Typical Culture Preservation Committee of the Chinese Academy of Sciences (Shanghai, China), and was maintained in KM medium (ScienCell Research Laboratories, Inc., San Diego, CA, USA). NSCLC cells (PC-9, sensitive to gefitinib; PC-9/GR, resistant to gefitinib) were maintained in Dulbecco's modified Eagle's medium (DMEM; Biological Industries, Kibbutz Beit Haemek, Israel). The cell lines PC-9 and PC-9/GR were kindly provided by Guangdong Lung Cancer Institute (Guangdong, China) and were described in a previous study (16).

Cell proliferation and apoptosis assay. Cells were equally seeded into 96 -well plates at $37^{\circ} \mathrm{C}$ for incubation overnight. Various fatty acids (C14:0, C15:0, C16:0, C17:0, C18:0, C18:1 or C20:0) (Sigma-Aldrich; Merck KGaA, Darmstadt, Germany) dissolved in anhydrous ethanol and filtered (17) were added at the indicated concentrations $(10,50,90,130,170,210$ or $250 \mu \mathrm{M}$ ), followed by incubation for $48 \mathrm{~h}$. The cells were then incubated with MTT for $4 \mathrm{~h}$ at room temperature and cell proliferation was determined using a spectrophotometer (Molecular Devices, LLC, Sunnyvale, CA, USA) by determining the optical density at OD $490 \mathrm{~nm}$. For apoptosis detection, an equal number of cells was washed with PBS and re-suspended in binding buffer contained in the Annexin V-fluorescein isothiocyanate (FITC) kit (TransGen Biotech Co., Ltd., Beijing, China). The cell suspension was then transferred to a new reaction tube and stained by Annexin V-FITC and propidium iodide (PI) according to the manufacturer's protocol. After incubation in the dark for $15 \mathrm{~min}$ at $25^{\circ} \mathrm{C}$, cells were re-suspended in binding buffer and subjected to apoptosis measurement by flow cytometry.

Cell migration assay. Cells were seeded in 6-well plates and cultured at $37^{\circ} \mathrm{C}$ with $5 \% \mathrm{CO}_{2}$, until the concentration reached $95 \%$. Cells were scratched with a sterile pipette tip to generate a cell-free path (width, $\sim 1 \mathrm{~mm}$ ) and cells were washed with PBS two times, followed by culture in DMEM (Biological Industries) containing the indicated fatty acids (C16:0, C17:0 or C18:0). After $48 \mathrm{~h}$ of incubation $37^{\circ} \mathrm{C}$, images of the cells were captured through a fluorescent microscope at low-magnification. The wound gaps were measured and the mean healing ratios were quantified with ImageJ software (National Institutes of Health, Bethesda, MA, USA).

Cell clone formation assay. PC-9 and PC-9/GR cells were seeded into a 6 -well plate at a density of 300 cells/well and incubated for $48 \mathrm{~h}$. The cells were refreshed with culture media with or without C17:0 (final concentraion, $50 \mu \mathrm{M}$ ) every $48 \mathrm{~h}$. Approximately 12-14 days later cells were fixed with $4 \%$ paraformaldehyde (Beijing Solarbio Science \& Technology Co., Ltd., Beijing, China) at $4^{\circ} \mathrm{C}$ for $30 \mathrm{~min}$ and stained with $0.1 \%$ crystal violet at $25^{\circ} \mathrm{C}$ for $10 \mathrm{~min}$ (Beijing Solarbio Science \& Technology Co., Ltd.) and cell images were captured with a fluorescence microscope and the number of cell colonies ( $>50$ colonies) was counted.

Fatty acid analysis of the cells by gas chromatography-mass spectrometry (GC-MS). Equal amounts of PC-9 and PC-9/GR cells were seeded for incubation overnight. Cells were incubated with or without C17:0 (final concentration, $100 \mu \mathrm{M}$ ) for $48 \mathrm{~h}$. The cells were then collected and washed with PBS three times. Cells were counted and a cell suspension was prepared with $3 \mathrm{ml} \mathrm{HCl}$-methanol ( $/ \mathrm{v}=5 \%)$, followed by the addition of $10 \mu \mathrm{l}$ of $\mathrm{C} 15: 0$ internal standard (C15:0 in chloroform, the final concentration, $5 \mathrm{mg} / \mathrm{ml}$ ). The tubes were sealed and heated in an incubator at $90^{\circ} \mathrm{C}$ for $4 \mathrm{~h}$. After natural cooling to room temperature, $4 \mathrm{ml} \mathrm{Na}_{2} \mathrm{CO}_{3}(\mathrm{w} / \mathrm{w}=10 \%$ ) was added. Subsequently $1 \mathrm{ml} \mathrm{n}$-hexane was added, followed by agitation for $5 \mathrm{~min}$ and centrifugation at $1,000 \times \mathrm{g}$ for $10 \mathrm{~min}$. A total of $400 \mu \mathrm{l}$ of supernatant containing methyl esters of fatty acids was transferred to an automatic injector vial and subjected to a GC-MS assay according to the manufacturer's protocol. In brief, the compositions of methyl esters of fatty acids in the cells were analyzed by a $30-\mathrm{m}$ polar capillary column $(0.32 \mathrm{~mm}$ internal diameter; SH-FameWax) on a Shimadzu gas chromatograph containing a flame ionization detector (GCMS-QP2010 Ultra; Shimadzu, Kyoto, Japan). Of the samples, $1 \mu$ l was injected (injector temperature, $240^{\circ} \mathrm{C}$ ). The column temperature was held at $130^{\circ} \mathrm{C}$ for $1 \mathrm{~min}$, and increased at a rate of $3^{\circ} \mathrm{C} / \mathrm{min}$ to $200^{\circ} \mathrm{C}$, then increased at a rate of $2^{\circ} \mathrm{C} / \mathrm{min}$ to $220^{\circ} \mathrm{C}$ and maintained for $10 \mathrm{~min}$. Fatty acids in cells were quantified by an internal standard method using C15:0 methyl ester.

Western blotting. Cells were collected and incubated with RIPA lysis buffer (Beyotime Institute of Biotechnology, Haimen, China), followed by centrifugation at $10,000 \mathrm{x} \mathrm{g}$, $4^{\circ} \mathrm{C}$ for $10 \mathrm{~min}$. Supernatants were harvested and total protein was quantified by a BCA assay. Total protein (30-60 $\mu \mathrm{g})$ was subjected to $10 \%$ SDS-PAGE and transferred onto polyvinylidene fluoride (PVDF) membranes, followed by blocking with TBST (10 mM Tris-HCl, $\mathrm{pH} 7.4,150 \mathrm{mM} \mathrm{NaCl}$ and $0.1 \%$ Tween-20) containing 5\% dried skimmed milk for $2 \mathrm{~h}$ at room temperature. Then the membranes were blotted with primary antibodies against GLUT1 (dilution 1:5,000; cat. no. ab115730; Abcam, Cambridge, UK), GLUT4 (dilution 1:2,000; cat. no. ab654; Abcam), p-S6K (dilution 1:1,000; cat. no. sc-8416; Santa Cruz Biotechnology, Dallas, TX, USA), S6K (dilution 1:1,000; cat. no. sc-8418; Santa Cruz Biotechnology), AKT (dilution 1:5,000; cat. no. ab179463; Abcam), p-AKT (dilution 1:5,000; cat. no. 81283; Abcam) 

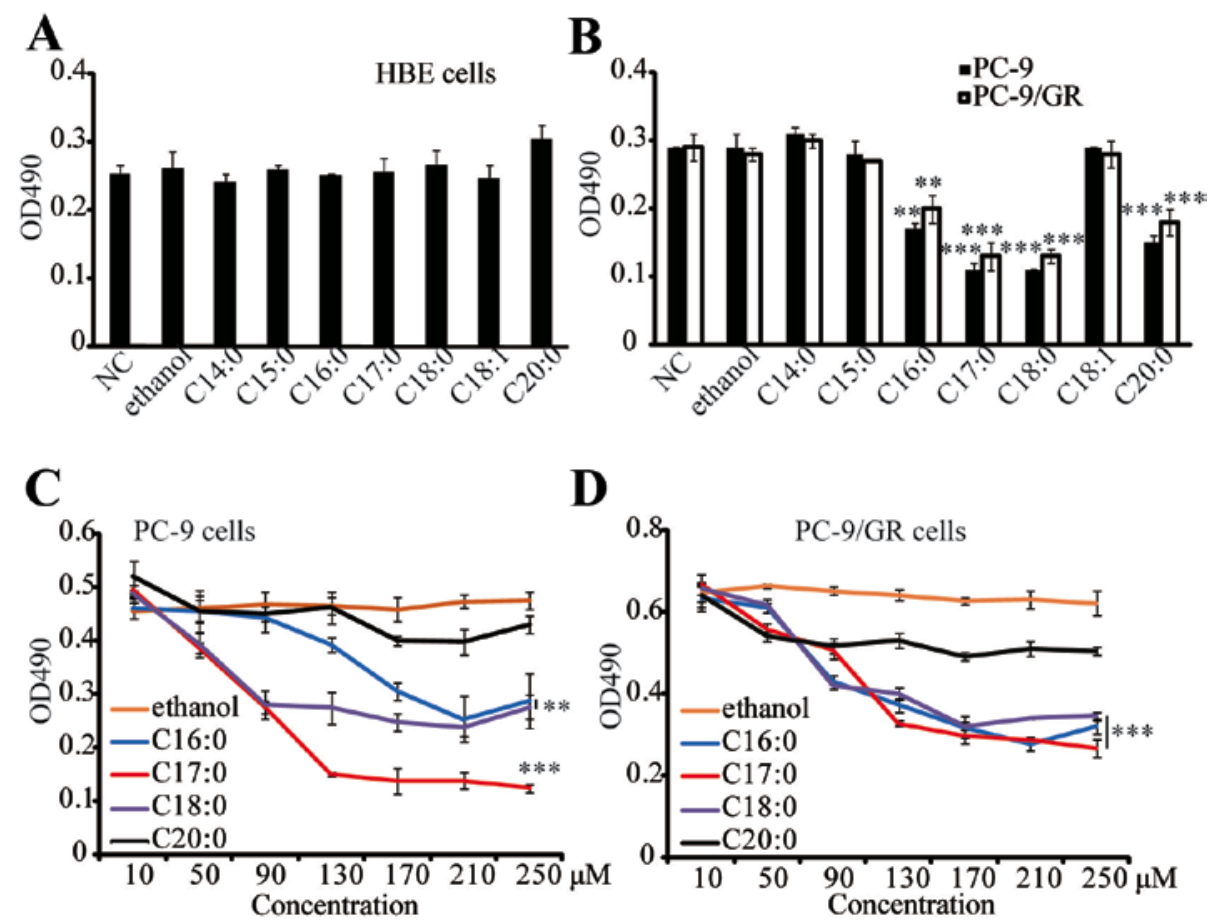

D

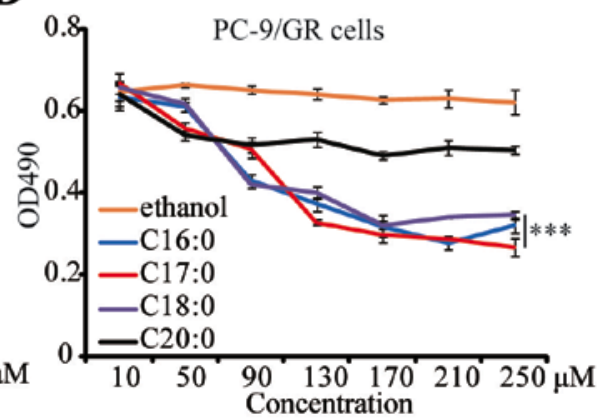

Figure 1. C17:0 inhibits PC-9 and PC-9/GR cell proliferation. (A) HBE $\left(3 \times 10^{3}\right)$ cells or (B) PC-9 and PC-9/GR cells were individually seeded in 96-well plates and incubated for attachment overnight. Each fatty acid was added at a final concentration of $100 \mu \mathrm{mol} / 1$, followed by incubation for $48 \mathrm{~h}$ and cell proliferation ratios were determined by a MTT assay. (C) PC-9 $\left(4 \times 10^{3}\right)$ and (D) PC-9/GR cells were prepared as aforementioned and treated with C17:0 at the indicated concentrations for $48 \mathrm{~h}$, followed by assessment of the cell proliferation ratios by a MTT assay. Values are expressed as the mean \pm standard deviation. ${ }^{* *} \mathrm{P}<0.01$, ${ }^{* * * *} \mathrm{P}<0.001$, experimental vs. the control group (ethanol group). C17:0, heptadecanoic acid; PC-9/GR, gefitinib-resistant PC-9 cell line; HBE, human bronchial epithelioid cell line.

and GAPDH (dilution 1:5,000; cat. no. ab181602; Abcam) at $4^{\circ} \mathrm{C}$, for overnight. After washing with TBST for three times, membranes were further incubated with secondary antibody goat anti-rabbit IgG-HRP (dilution 1:5,000; cat. no. AS014; ABclonal) or goat anti-mouse IgG-HRP (dilution 1:5,000; cat. no. AS003; ABclonal) for $1 \mathrm{~h}$ at room temperature. At the end, the membranes were incubated with a ECL kit (cwbiotech) and subjected to exposure with X-ray films in dark room.

Statistical analysis. Differences between two groups were statistically analyzed by one-way analysis of variance with a Tukey's post hoc test using SPSS 19.0 software (IBM Corp., Armonk, NY, USA). All experiments were performed at least three times. Results were expressed as the mean \pm standard deviation. $\mathrm{P}<0.05$ was considered to indicate a statistically significant difference.

\section{Results}

C17:0 inhibits PC-9 and PC-9/GR cell proliferation. Dietary saturated fatty acids may exert antitumor effects, and screening functional fatty acids may provide candidates that may serve as adjuvants in cancer therapy. Beef tallow and mutton tallow are common dietary animal oils. C16:0, C18:0 and C18:1 are the three dominant fatty acids in beef and mutton tallow. In a preliminary analysis, the content of C17:0 was determined to be $2.09 \%$ in beef tallow and $2.05 \%$ in mutton tallow (data not shown).

To investigate the impact of major dietary fatty acids from ruminant animal oils on lung cancer cells, a cell proliferation assay was performed. C14:0, C15:0, C16:0, C17:0, C18:0, C18:1 or C20:0 were directly added into HBE, PC-9 and PC-9/GR cells. As presented in Fig. 1A and B, the results of the MTT assay indicated that these fatty acids did not affect the proliferation of HBE cells, while 4 types of fatty acids (C16:0, C17:0, C18:0 and C20:0) significantly inhibited the proliferation of PC-9 and PC-9/GR cells. Furthermore, C17:0 was identified to be the most effective fatty acid against PC-9 and PC-9/GR cells, and its effects were dose-dependent (Fig. 1C and D). The effect of C17:0 in other lung cancer cells, including A549 and H1975, was also examined. Similarly, the results revealed that C17:0 inhibited cell proliferation in A549 and H1975 (data not shown). These results indicated that C17:0 may be a fatty acid suitable for lung cancer treatment.

C17:0 inhibits cell migration, clone formation and promotes apoptosis of PC-9 and PC-9/GR cells. The present study then focused on the functional role of C17:0 in lung cancer cells. A wound healing assay indicated that $\mathrm{C} 16: 0, \mathrm{C} 17: 0$ and $\mathrm{C} 18: 0$ inhibited the wound closure ratio of PC-9 and PC-9/GR cells (Fig. 2A and B). Furthermore, the impact of C17:0 on cell migration was the greatest among all fatty acids tested. The apoptosis ratio was also determined by flow cytometry. As presented in Fig. 3A, C17:0 induced 16.62 and 29.63\% apoptosis in PC-9 cells and PC-9/GR cells respectively. C18:0 also performed similarly in the two cell line variants. In addition, the results of the cell clone formation assay indicated that C17:0 suppressed the proliferation of PC-9 and PC-9/GR cells (Fig. 3B). These results indicated that $\mathrm{C} 17: 0$ treatment in PC-9 and PC-9/GR cells was able to induce lung cancer cell death. 

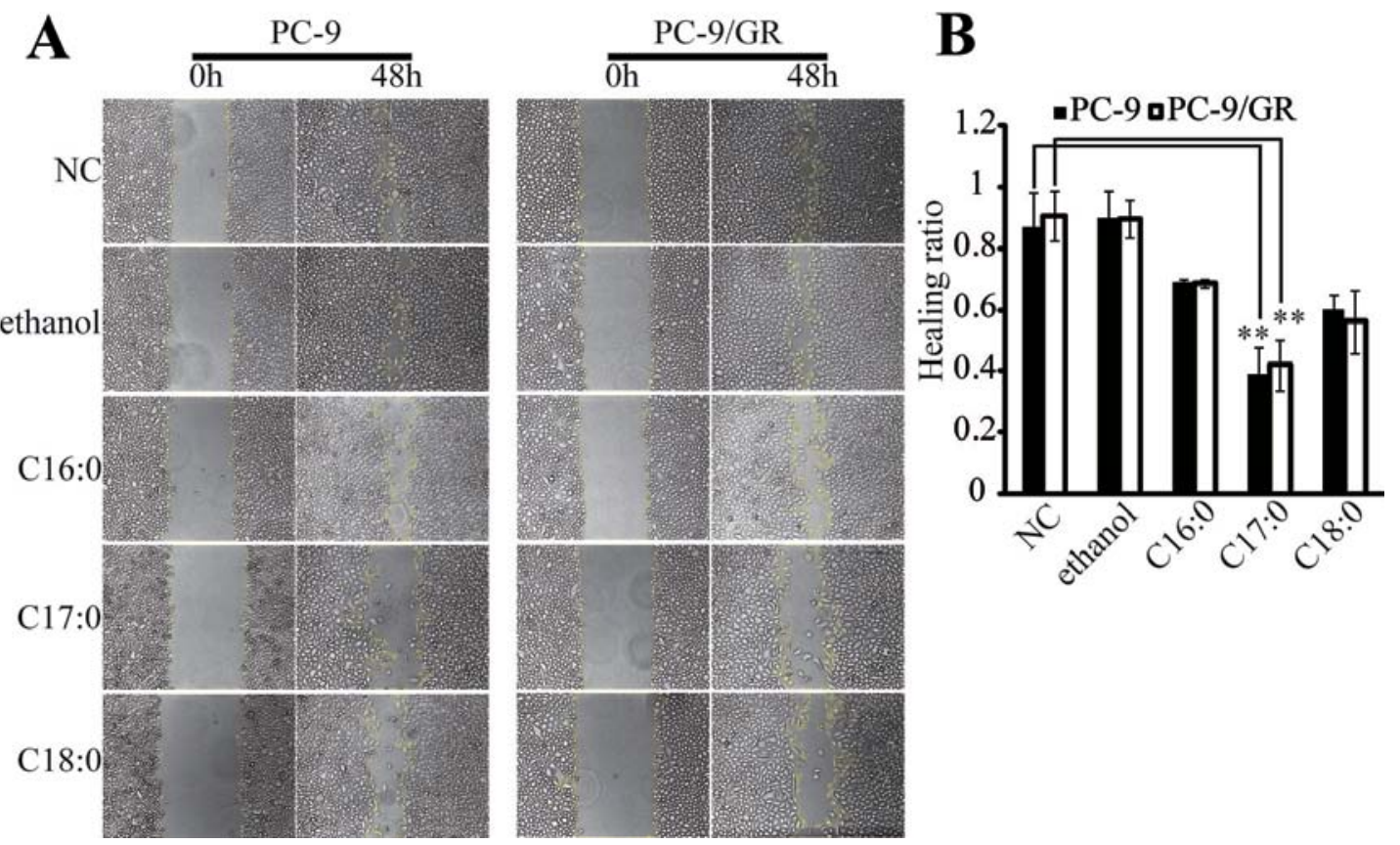

Figure 2. C17:0 inhibits wound healing in PC-9 and PC-9/GR cells. (A) PC-9 and PC-9/GR cells were seeded in 6-well plates and incubated for attachment overnight. A scratch was made in the confluent cell layer by using a pipette tip and culture media with various fatty acids (100 $\mu \mathrm{M})$, without serum was added, followed by incubation for $48 \mathrm{~h}$. Finally, images of the cells were captured using an optical microscope. (B) Cell layer wound healing ratios in each group were statistically analyzed with ImageJ software. Values are expressed as the mean \pm standard deviation. ${ }^{* *} \mathrm{P}<0.01$, experimental vs. the control group (NC group). C17:0, heptadecanoic acid; PC-9/GR, gefitinib-resistant PC-9 cell line.
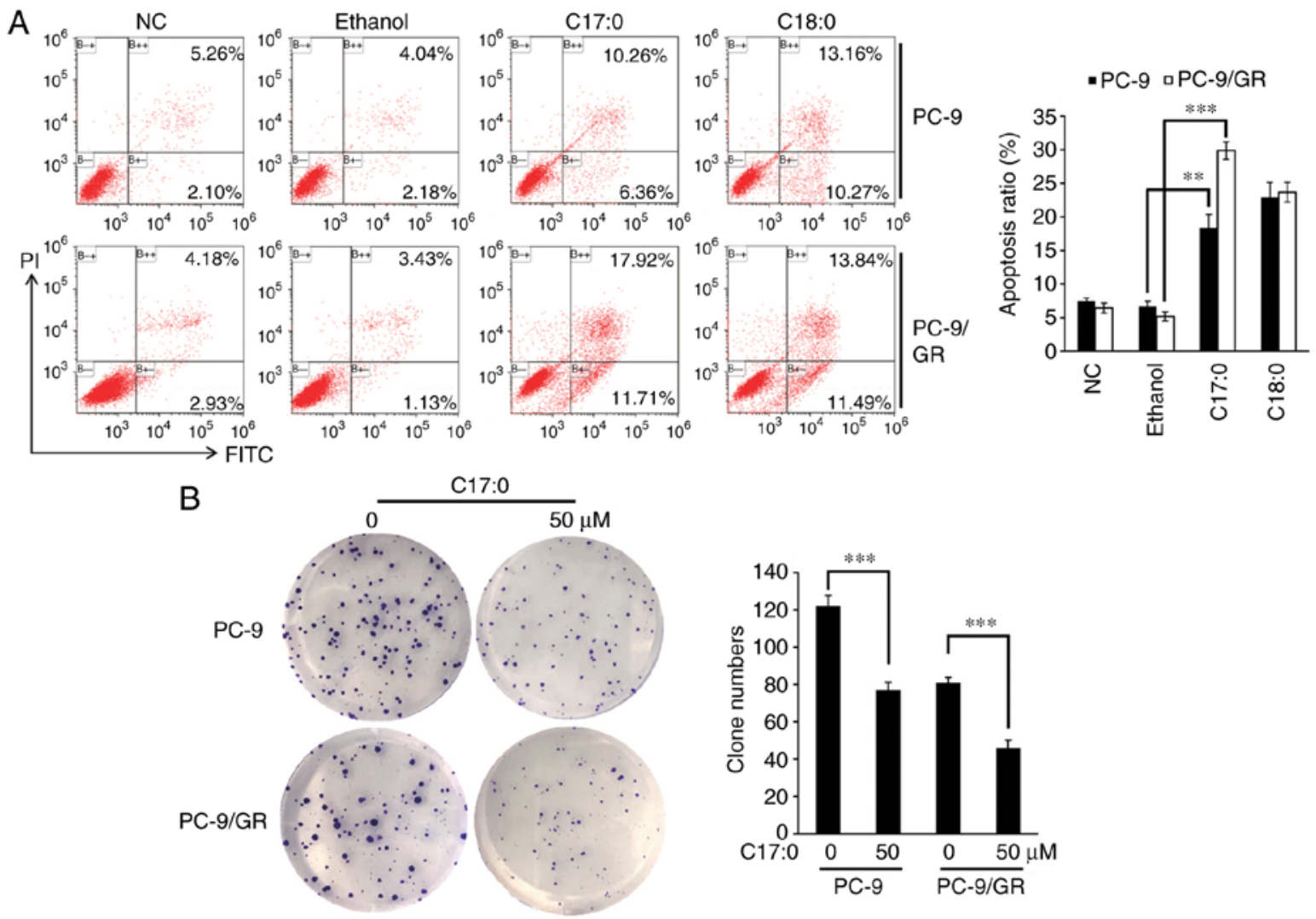

Figure 3. C17:0 promotes apoptosis, while it inhibits clone formation in PC-9 and PC-9/GR cells. (A) PC-9 and PC-9/GR cells were seeded in 6-well plates and incubated overnight. C17:0 or C18:0 was then added to the cells and after $48 \mathrm{~h}$ of incubation, the cells were harvested and stained with FITC-Annexin V and PI. Finally, cell apoptosis ratios in each group were determined by flow cytometry. (B) PC-9 and PC-9/GR cells were seeded in a 6-well plate and incubated for $48 \mathrm{~h}$. The cells were refreshed with media containing C17:0 (final concentration, $50 \mu \mathrm{M}$ ) or without C17:0 every $48 \mathrm{~h}$. After 12-14 days of culture, visible cell colonies were fixed and stained. The number of cell colonies was counted under a microscope. Values are expressed as the mean \pm standard deviation. ${ }^{* *} \mathrm{P}<0.01$, ${ }^{* * * *} \mathrm{P}<0.001$, experimental vs. the control group (ethanol group). C17:0, heptadecanoic acid; C18:0, octadecanoic acid; PC-9/GR, gefitinib-resistant PC-9 cell line; PI, propidium iodide; FITC, fluorescein isothiocyanate. 
A

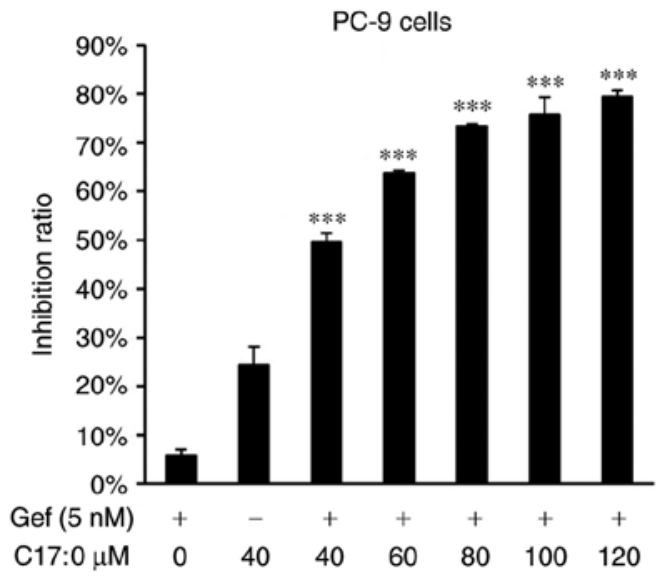

B

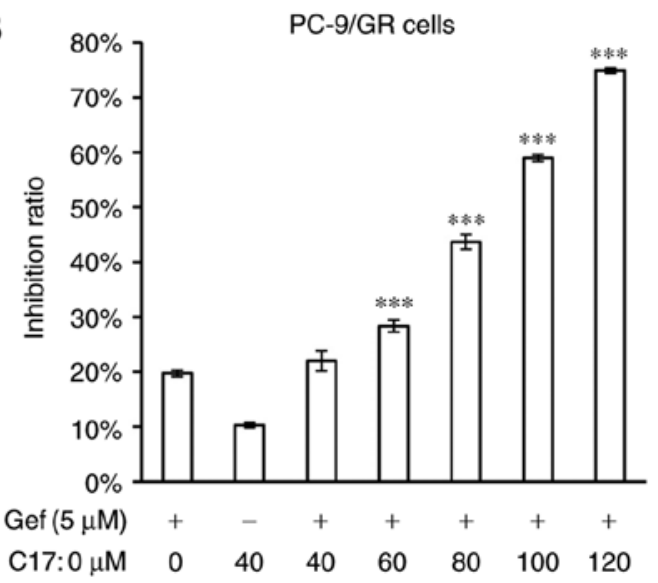

Figure 4. C17:0 promotes the cytotoxic effect of gefitinib in PC-9 and PC-9/GR cells. PC-9 and PC-9/GR cells were seeded into 96-well plates. Gefitinib $(5 \mathrm{nM})$ plus C17:0 with indicated concentrations were added into PC-9 cells. In addition, PC-9/GR cells were incubated with $5 \mu \mathrm{M}$ Gefitinib and C17:0 with varying concentrations. After $48 \mathrm{~h}$ of incubation, cell inhibition ratios in (A) PC-9 cells and (B) PC-9/GR cells were assessed by an MTT assay. Inhibition ratio $=\left(\mathrm{OD}_{\text {control }} \mathrm{OD}_{\text {treated }}\right) / \mathrm{OD}_{\text {control }} \times 100 \%$. Values are expressed as the mean \pm standard deviation. ${ }^{* * *} \mathrm{P}<0.001$, experimental vs. the control group. C17:0, heptadecanoic acid; PC-9/GR, gefitinib-resistant PC-9 cell line.

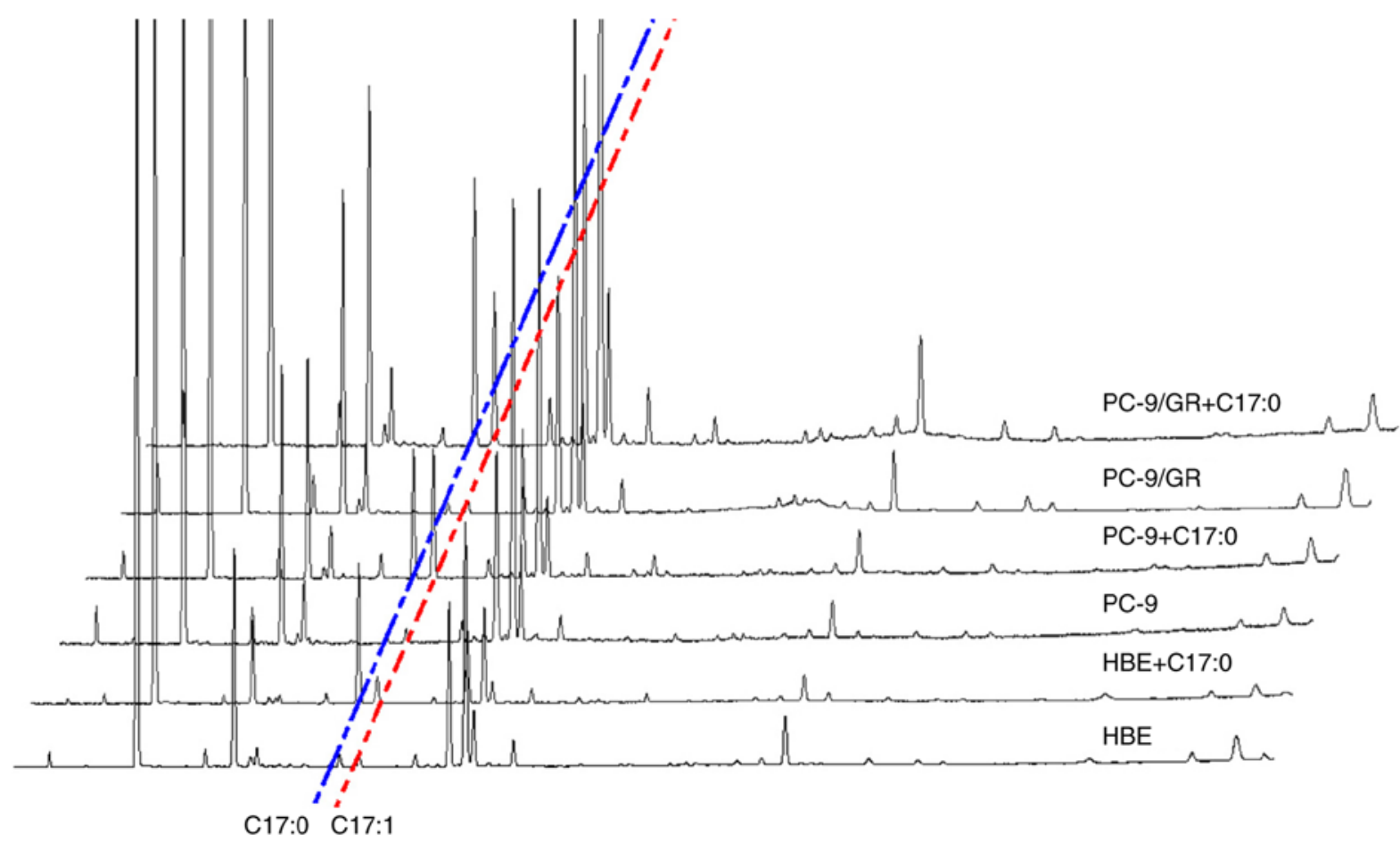

Figure 5. Fatty acid composition assay in HBE, as well as and PC-9 and PC-9/GR cells. Equal amounts of HBE, PC-9 and PC-9/GR cells were seeded into plates and incubated overnight. C17:0 was added and the cells were incubated for $48 \mathrm{~h}$. The cells were collected and subjected to a GC-MS assay according to the manufacturer's protocol. C17:0, heptadecanoic acid; PC-9/GR, gefitinib-resistant PC-9 cell line; HBE, human bronchial epithelioid cell line.

C17:0 enhances the cytotoxicity of gefitinib in PC-9 and $P C-9 / G R$ cells. EGFR-TKIs are widely used in lung cancer therapy and exhibit marked efficacy. To investigate the additive/enhancing effect of C17:0 on EGFR-TKIs, an MTT assay was also performed on PC-9 and PC-9/GR cells treated with gefitinib plus C17:0. As presented in Fig. 4A and B, C17:0 promoted the inhibitory effect of gefitinib in PC-9 and PC-9/GR cells in a dose-dependent manner. The greatest inhibition ratio in the two cell variants reached $\sim 80 \%$. These results indicated that C17:0 at increasing concentrations enhanced the effect of gefitinib on NSCLC cells in vitro.
Effect of C17:0 on the fatty acid composition of PC-9 and $P C-9 / G R$ cells. Changes in the fatty acid composition of PC-9 and PC-9/GR cells in response to C17:0 treatment was assessed by GC-MS and C15:0 was used as the internal standard. As presented in Fig. 5 and Table I, the contents of various fatty acids ranging from C14:0 to C24:0 were analyzed. In HBE, PC-9 and PC-9/GR cells, the addition of C17:0 increased the content of 10-cis-heptadecenoic acid (C17:1). The concentration of C17:1 in PC-9 and PC-9/GR cells was higher than that in HBE cells. Furthermore, the concentration of C18:1 in HBE cells was lower than that in PC-9 and PC-9/GR cells. In response 
Table I. Fatty acid composition analysis.

\begin{tabular}{|c|c|c|c|c|c|c|}
\hline & HBE & $\mathrm{HBE}+\mathrm{C} 17: 0$ & PC-9 & PC-9+C17:0 & PC-9/GR & PC-9/GR+C17:0 \\
\hline $\mathrm{C} 14: 0$ & $0.64 \pm 0.07$ & $0.33 \pm 0.04^{b}$ & $1.41 \pm 0.26$ & $1.32 \pm 0.11^{\mathrm{b}}$ & $1.45 \pm 0.06$ & $1.16 \pm 0.04^{b}$ \\
\hline C16:0 & $12.12 \pm 1.02$ & $7.4 \pm 0.73^{\mathrm{b}}$ & $14.8 \pm 0.55$ & $12.6 \pm 0.46$ & $12.64 \pm 0.17$ & $9.98 \pm 0.1^{\mathrm{c}}$ \\
\hline C16:1 & $1.97 \pm 0.34$ & $1.04 \pm 0.02^{\mathrm{b}}$ & $4.9 \pm 0.63$ & $4.27 \pm 0.59$ & $3.38 \pm 0.18$ & $2.71 \pm 0.04^{\mathrm{b}}$ \\
\hline C17:0 & $0.7 \pm 0.2$ & $12.99 \pm 0.42^{\mathrm{c}}$ & $0.47 \pm 0.18$ & $7.56 \pm 0.48^{c}$ & $0.39 \pm 0.05$ & $8.09 \pm 0.1^{\mathrm{c}}$ \\
\hline $\mathrm{C} 17: 1$ & $0.43 \pm 0.39$ & $2.83 \pm 0.1^{\mathrm{c}}$ & $0.9 \pm 0.3$ & $8.58 \pm 0.29^{c}$ & $0.31 \pm 0.27$ & $4.56 \pm 0.14^{\mathrm{c}}$ \\
\hline C18:0 & $10.8 \pm 1.08$ & $7.97 \pm 0.78^{b}$ & $10.98 \pm 1.3$ & $9.18 \pm 0.67$ & $10.78 \pm 0.44$ & $11.84 \pm 0.49^{\mathrm{a}}$ \\
\hline C18:1 & $20.03 \pm 1.69$ & $12.71 \pm 1.63^{\mathrm{b}}$ & $35.32 \pm 1.07$ & $36.98 \pm 3.98$ & $29.16 \pm 0.71$ & $33.15 \pm 0.81^{\mathrm{b}}$ \\
\hline C18:2 & $1.65 \pm 0.27$ & $1.33 \pm 0.12$ & $1.29 \pm 0.3$ & $1.44 \pm 0.05$ & $1.41 \pm 0.04$ & $1.8 \pm 0.05^{\mathrm{b}}$ \\
\hline C19:0 & $0 \pm 0$ & $0.44 \pm 0.03^{c}$ & $0 \pm 0$ & $0 \pm 0$ & $0 \pm 0$ & $0 \pm 0$ \\
\hline C20:0 & $0 \pm 0$ & $0 \pm 0$ & $0 \pm 0$ & $0 \pm 0$ & $0.12 \pm 0.2$ & $0 \pm 0$ \\
\hline C20:1 & $0.24 \pm 0.22$ & $0 \pm 0$ & $0.23 \pm 0.06$ & $0 \pm 0^{\mathrm{b}}$ & $0.28 \pm 0.3$ & $0.31 \pm 0.01$ \\
\hline C20:3 & $0.59 \pm 0.55$ & $0.29 \pm 0.04$ & $0.49 \pm 0.09$ & $0.22 \pm 0.2$ & $0.2 \pm 0.18$ & $0.39 \pm 0.34$ \\
\hline C18:3 & $0 \pm 0$ & $0 \pm 0$ & $0 \pm 0$ & $0 \pm 0$ & $0.11 \pm 0.19$ & $0.2 \pm 0.35$ \\
\hline C20:4 & $3.96 \pm 0.48$ & $3.13 \pm 0.01^{\mathrm{b}}$ & $2.68 \pm 0.5$ & $2.86 \pm 0.13$ & $3.08 \pm 0.32$ & $3.95 \pm 0.42^{\mathrm{a}}$ \\
\hline C20:5 & $0.39 \pm 0.36$ & $0.59 \pm 0.06$ & $0.14 \pm 0.25$ & $0 \pm 0$ & $0.28 \pm 0.26$ & $0.44 \pm 0.38$ \\
\hline $\mathrm{C} 22: 0$ & $0.22 \pm 0.23$ & $0 \pm 0$ & $0.21 \pm 0.36$ & $0 \pm 0$ & $0.17 \pm 0.3$ & $0 \pm 0$ \\
\hline $\mathrm{C} 22: 1$ & $0 \pm 0$ & $0 \pm 0$ & $0 \pm 0$ & $0 \pm 0$ & $0.15 \pm 0.25$ & $0 \pm 0$ \\
\hline $\mathrm{C} 22: 4$ & $0.23 \pm 0.25$ & $0 \pm 0$ & $0.18 \pm 0.31$ & $0 \pm 0$ & $0.35 \pm 0.31$ & $0.24 \pm 0.42$ \\
\hline$C 22: 6$ & $3.17 \pm 0.79$ & $1.81 \pm 0.32^{b}$ & $2.07 \pm 0.75$ & $2.19 \pm 0.9$ & $2.81 \pm 0.66$ & $2.14 \pm 0.34$ \\
\hline $\mathrm{C} 24: 0$ & $0.45 \pm 0.4$ & $0 \pm 0$ & $0 \pm 0$ & $0 \pm 0$ & $0 \pm 0$ & $0 \pm 0$ \\
\hline
\end{tabular}

Numbers represent the ratios of each fatty acid to the internal standard $(\mathrm{C} 15: 0)$. ${ }^{\mathrm{a}} \mathrm{P}<0.05,{ }^{\mathrm{b}} \mathrm{P}<0.01$ and ${ }^{\mathrm{c}} \mathrm{P}<0.001$ compared to each control group. ND, not detected.

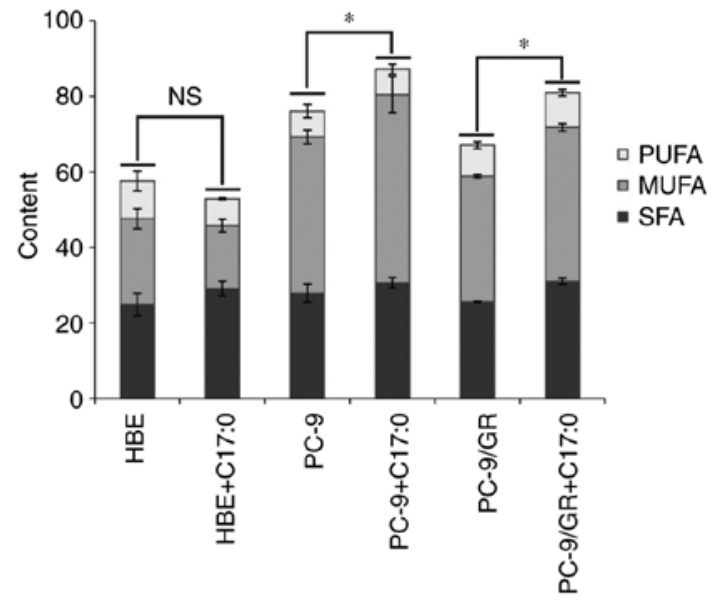

Figure 6. Fatty acid composition assay by GC-MS. Equal amounts of HBE, PC-9 and PC-9/GR cells were seeded into plates and incubated overnight. $\mathrm{C} 17: 0$ was then added and the cells were incubated for $48 \mathrm{~h}$, followed by collection and analysis using the GC-MS assay. The ratios of SFA, MUFA and PUFA were statistically analyzed. The ratios of total fatty acids in the control group and C17:0-treated group were preceded to statistical analysis. Values are expressed as the mean \pm standard deviation. ${ }^{*} \mathrm{P}<0.05$, experimental vs. the control group. C17:0, heptadecanoic acid; PC-9/GR, gefitinib-resistant PC-9 cell line; HBE, human bronchial epithelioid cell line; GC-MS, gas chromatography-mass spectrometry; SFA, saturated fatty acid; MUFA, monounsaturated fatty acid; PUFA, polyunsaturated fatty acid.

to the addition of $\mathrm{C} 17: 0, \mathrm{C} 18: 1$ was identified to be downregulated in HBE cells, while it was not altered in PC-9 cells and only slightly upregulated in PC-9/GR cells. In HBE cells, the total fatty acid composition was not altered during incubation with C17:0. However, the ratio of total fatty acids in PC-9 and PC-9/GR cells was higher than that in HBE cells, indicating that these lung cancer cells have a higher lipid synthesis activity and accumulation (Fig. 6). The increase of C17:1 in PC-9/GR cells may contribute to lung cancer cell death.

C17:0 inhibits the activation of PI3K/Akt signaling in PC-9 and PC-9/GR cells. To further explore the molecular mechanisms associated with the inhibition of C17:0 on PC-9 and PC-9/GR cells, the activation of relevant signaling pathways was detected. The PI3K/Akt signaling pathway is one pivotal pathway regulating cell proliferation and tumor development. Therefore, its activation was detected in PC-9 and PC-9/GR cells in response to treatment with $\mathrm{C} 17: 0$. As presented in Fig. 7, the phosphorylation of Akt and S6K was inhibited. In particular, the levels of p-S6K in PC-9/GR cells were markedly downregulated by $\mathrm{C} 17: 0$ in a dose-dependent manner. In general, cancer cells may upregulate the expression or enhance the activation of glucose transporters, including GLUT1 and GLUT4, to increase glucose import from the extracellular environment into the cytoplasm to compensate ATP production (18). Thus, the expression of GLUT1 and GLUT4 in the two cell line variants in the absence or presence of C17:0 was also detected. The results indicated that treatment of PC-9 and PC-9/GR cells with C17:0 caused downregulation of GLUT1 and GLUT4. Collectively, the present results indicated that addition of C17:0 to PC-9 and PC-9/GR cells inhibited the activation of PI3K/Akt signaling and glucose consumption. 


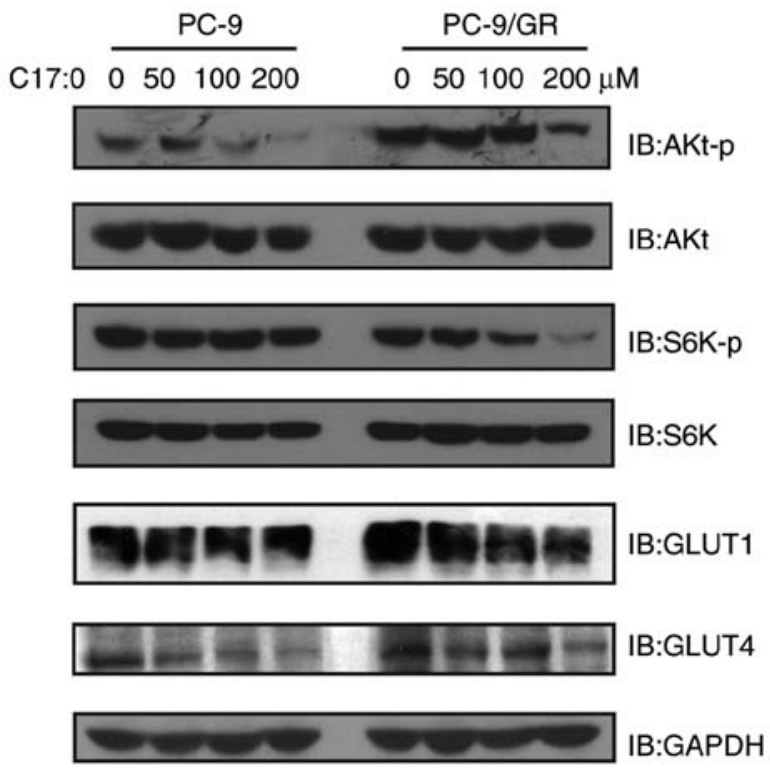

Figure 7. C17:0 inhibits PI3K/Akt signaling in PC-9 and PC-9/GR cells. PC-9 and PC-9/GR cells were equally seeded in 35-mm plates and incubated overnight. C17:0 with varying concentrations was added, followed by incubation for 48 h. Cells were harvested and subjected to SDS-PAGE and immunoblotting assay with the indicated antibodies. C17:0, heptadecanoic acid; PC-9/GR, gefitinib-resistant PC-9 cell line.

\section{Discussion}

Recently, alteration of lipid metabolism in cancer cells has drawn increasing attention. Accumulating studies have reported that lipid metabolism is associated with lung cancer development and resistance therapies, including chemotherapy (19-23). Modulation of metabolic pathways has been demonstrated to control cancer cell proliferation and death, indicating that application of relative molecules or reagents involved in this process may be beneficial for cancer therapy. Fatty acids from dietary oils are the major substrates for lipid synthase. The amounts and types of fatty acids ingested are important for nutritional therapy in patients with cancer. Polyunsaturated fatty acids (PUFAs) have also been demonstrated to inhibit colon cancer cell growth (24). Palmitic acid has been demonstrated to impair hepatocellular carcinoma development by suppressing cell membrane fluidity and glucose intake (25). These studies indicate that functional fatty acids may be beneficial for clinical cancer therapy. Therefore investigation of the association between fatty acid intake and lung cancer development may provide nutritional suggestions for patients receiving lung cancer therapy. In the present study, the effects of major dietary fatty acids derived from ruminant animal oils in lung cancer cells were assessed using the PC-9 cell line and its derivative with acquired gefitinib-resistance PC-9/GR. The results indicated that C17:0 significantly inhibited the proliferation and migration of the two cell line variants. Furthermore, treatment with $\mathrm{C} 17: 0$ induced greater apoptosis in PC-9 and PC-9/GR cells. The results of the MTT assay also indicated that C17:0 enhanced the cytotoxic effect of gefitinib. The present study demonstrated the role and function of C17:0 in NSCLC and provided a potential application in clinical treatment.
First, it was demonstrated that various concentrations of C16:0, C17:0, C18:0 and C20:0 inhibit PC-9 and PC-9/GR cells. Further study indicated that $\mathrm{C} 17: 0$ had the greatest cytotoxic effect in PC-9 cells, confirming that C17:0 is able to inhibit NSCLC cells. This result indicated that certain saturated fatty acids are able to inhibit tumor cell proliferation. Of note, a previous study argued that saturated fatty acids are not the primary cause for certain diseases, including arterial occlusion (26). Therefore, saturated fatty acids may have a potential function regarding health and diseases, which requires further study and rational analysis. In addition, C15:0 was not effective in PC-9 and PC-9/GR cells, while C17:0 was particularly effective in NSCLC cells. The effect of OCS-FAs with different lengths of carbon chain on NSCLC may also require further study to provide more functional fatty acids for lung cancers. Notably, C18:1 and cis-9,10-epoxy stearic acid, an oxidation product of $\mathrm{C} 18: 1$, have been previously reported to be effective in decreasing the cell viability of HepG2 cells (27). However, the addition of C18:1 did not affect the viability in PC-9 and PC-9/GR cells in the present study, indicating that certain fatty acids may exert a different impact on different tumor cell types.

Certain OBCFAs have been demonstrated to be effective against certain types of tumor cells, e.g. breast cancer (28), indicating that straight odd-chain or branched-chain fatty acids may exert similar effects on tumor cells. The present results indicated that $\mathrm{C} 17: 0$ significantly suppressed wound healing in PC-9 and PC-9/GR cells. Furthermore, C17:0 produced a greater increase in FITC-Annexin $\mathrm{V}$ and PI-stained cells, suggesting that C17:0 triggers cell apoptosis. Similarly, omega-3 PUFAs have been demonstrated to inhibit A549 cell proliferation by promoting apoptosis and inhibiting the PI3K/Akt signaling pathway (29). In the present study, the impact of C17:0 on apoptosis and relevant signaling pathways was also evaluated. The results were consistent with those of the aforementioned study, indicating that C17:0 and omega-3 PUFA/docosahexenoic acid inhibit lung cancer cells via a similar mechanism. Furthermore, potential changes in the fatty acid profiles in the cell lines upon treatment with $\mathrm{C} 17: 0$ were detected. An increase of C17:1 was observed in two cell lines after supplementation with $\mathrm{C} 17: 0$. The function of $\mathrm{C} 17: 1$ in lung cancer cells remains elusive. However, stearoyl-CoA desaturase-1, a key rate-limiting enzyme for monounsaturated fatty acid (MUFA) synthesis, has been revealed to be involved in maintaining rapid cell proliferation, apoptosis evasion, cancer cell development and transformation in a panel of cancer types, including lung cancer $(30,31)$. The alteration of MUFAs is correlated with cancer development, which may be contrary to the present results, as no alteration of C17:1 was detected in these studies. The results of the present study indicated that $\mathrm{C} 17: 1$ may inhibit lung cancer cell proliferation. Furthermore, supplementation of $\mathrm{C} 17: 0$ increased the ratios of C18:2 and C20:4, which may contribute to enhanced oxidative stress and cell death. The function of C17:0 and C17:1 in lung cancer cells requires a more comprehensive analysis.

To evaluate the effect of EGFR-TKIs plus C17:0 on NSCLC, PC-9 and PC-9/GR cells treated with a combination of $\mathrm{C} 17: 0$ and gefitinib were subjected to MTT assays. C17:0 was indicated to enhance the inhibitory effect of gefitinib on PC-9 as well as PC-9/GR cells. This combination effect was 
greater in PC-9 cells than that in PC-9/GR cells, consistent with the effects of $\mathrm{C} 17: 0$ in the two cell line variants alone. These results indicated that $\mathrm{C} 17: 0$ may be a suitable candidate for nutritional therapy for lung cancer. In fact, there are some references concerning the physiological concentration of C17:0 in humans. The OCS-FAs are one class of fatty acids with insignificant plasma concentrations, which account for $<0.5 \%$ total plasma fatty acid concentration and their varying range in blood plasma is $0-1 \%(32,33)$. Therefore, the physiological concentration of C17:0 is low. However, studies have reported that $\mathrm{C} 17: 0$ is a biomarker or potential protective fatty acid against a series diseases, such as metabolic syndrome and type 2 diabetes (34-36). In addition, C17:0 concentration in plasma could be elevated successfully by increasing people's dietary intake of C17:0-rich dairy food $(37,38)$. For example, a study reported that the intake of conventional dairy products containing $1 \%$ milk, $1.5 \%$ yogurt and $34 \%$ cheese could increase the level of cardioprotective fatty acid C15:0 and $\mathrm{C} 17: 0$ and have a minor effect on the lipid profile (38). C17:0 is high in milk and whole fat yogurt. Thus, we propose that $\mathrm{C} 17: 0$ may be a potential contributor for clinical treatment of lung cancer. Supplementation of n-3 PUFAs has been demonstrated to be effective to increase body weight and control the inflammatory status of patients with lung cancer clinically $(39,40)$. Therefore, further study of EGFR-TKIs plus C17:0 in vivo is required to validate the efficacy of C17:0 in lung cancer treatment.

\section{Acknowledgements}

We would like to thank all the staff at the Public Experiment Platform of the Institute of Health Sciences, Anhui University for their help in GC-MS and flow cytometric experiments.

\section{Funding}

The present study was supported, in part by the National Natural Science Foundation of China (grant no. 31600749), the Key Research and Development Projects in Anhui Province (1704a07020075), the College Students' Innovation and Entrepreneurship Training Project in Anhui Province (201810357296), and the Initial Foundation of Doctoral Scientific Research in Anhui University (Y01001487).

\section{Availability of data and materials}

The datasets/materials used in our present study are available from the corresponding author through reasonable request.

\section{Authors' contributions}

CX, PW, JG and LZ performed the main experiments and collected the data. TM and BM conducted the GC-MS assays, collected and analyzed the data. SY, GS and YY conducted the flow cytometric assays, collected and analyzed the data. $\mathrm{CX}, \mathrm{XH}, \mathrm{XY}$ and BZ designed the study, analyzed and drafted the manuscript. All authors read and approved the manuscript and agree to be accountable for all aspects of the research in ensuring that the accuracy or integrity of any part of the work are appropriately investigated and resolved.

\section{Ethics approval and consent to participate}

Not applicable.

\section{Patient consent for publication}

Not applicable.

\section{Competing interests}

The authors declare that they have no competing interests.

\section{References}

1. Torre LA, Bray F, Siegel RL, Ferlay J, Lortet-Tieulent J and Jemal A: Global cancer statistics, 2012. CA Cancer J Clin 65: 87-108, 2015

2. Pao W and Chmielecki J: Rational, biologically based treatment of EGFR-mutant non-small-cell lung cancer. Nat Rev Cancer 10: 760-774, 2010.

3. Maemondo M, Inoue A, Kobayashi K, Sugawara S, Oizumi S, Isobe $\mathrm{H}$, Gemma A, Harada M, Yoshizawa H, Kinoshita I, et al: Gefitinib or chemotherapy for non-small-cell lung cancer with mutated EGFR. N Engl J Med 362: 2380-2388, 2010.

4. Sequist LV, Yang JC, Yamamoto N, O'Byrne K, Hirsh V, Mok T, Geater SL, Orlov S, Tsai CM, Boyer M, et al: Phase III study of afatinib or cisplatin plus pemetrexed in patients with metastatic lung adenocarcinoma with EGFR mutations. J Clin Oncol 31: 3327-3334, 2013.

5. Yun CH, Mengwasser KE, Toms AV, Woo MS, Greulich H, Wong KK, Meyerson M and Eck MJ: The T790M mutation in EGFR kinase causes drug resistance by increasing the affinity for ATP. Proc Natl Acad Sci USA 105: 2070-2075, 2008.

6. Knott SRV, Wagenblast E, Khan S, Kim SY, Soto M, Wagner M, Turgeon MO, Fish L, Erard N, Gable AL, et al: Asparagine bioavailability governs metastasis in a model of breast cancer. Nature 554: 378-381, 2018.

7. Chen M, Wan L, Zhang J, Zhang J, Mendez L, Clohessy JG, Berry K, Victor J, Yin Q, Zhu Y, et al: Deregulated PP1alpha phosphatase activity towards MAPK activation is antagonized by a tumor suppressive failsafe mechanism. Nature communications 9: 159, 2018.

8. Chen M, Zhang J, Sampieri K, Clohessy JG, Mendez L, Gonzalez-Billalabeitia E, Liu XS, Lee YR, Fung J, Katon JM, et al: An aberrant SREBP-dependent lipogenic program promotes metastatic prostate cancer. Nat Genet 50: 206-218, 2018.

9. Khaw KT, Friesen MD, Riboli E, Luben R and Wareham N: Plasma phospholipid fatty acid concentration and incident coronary heart disease in men and women: The EPIC-Norfolk prospective study. PLoS Med 9: e1001255, 2012.

10. MeiklePJ,WongG,BarlowCK,WeirJM,GreeveMA,MacIntoshGL, Almasy L, Comuzzie AG, Mahaney MC, Kowalczyk A, et al: Plasma lipid profiling shows similar associations with prediabetes and type 2 diabetes. PLoS One 8: e74341, 2013.

11. Holman RT, Johnson SB and Kokmen E: Deficiencies of polyunsaturated fatty acids and replacement by nonessential fatty acids in plasma lipids in multiple sclerosis. Proc Natl Acad Sci USA 86: 4720-4724, 1989.

12. Fonteh AN, Cipolla M, Chiang J, Arakaki X and Harrington MG: Human cerebrospinal fluid fatty acid levels differ between supernatant fluid and brain-derived nanoparticle fractions, and are altered in Alzheimer's disease. PLoS One 9: e100519, 2014.

13. Adamska A and Rutkowska J: Odd- and branched-chain fatty acids in milk fat-characteristic and health properties. Postepy Hig Med Dosw (Online) 68: 998-1007, 2014 (In Polish).

14. Yang Z, Liu S, Chen X, Chen H, Huang $M$ and Zheng J: Induction of apoptotic cell death and in vivo growth inhibition of human cancer cells by a saturated branched-chain fatty acid, 13-methyltetradecanoic acid. Cancer Res 60: 505-509, 2000.

15. Fukuzawa M, Yamaguchi R, Hide I, Chen Z, Hirai Y, Sugimoto A, Yasuhara T and Nakata Y: Possible involvement of long chain fatty acids in the spores of Ganoderma lucidum (Reishi Houshi) to its anti-tumor activity. Biol Pharm Bull 31: 1933-1937, 2008 
16. Fei SJ, Zhang XC, Dong S, Cheng H, Zhang YF, Huang L, Zhou HY, Xie Z, Chen ZH and Wu YL: Targeting mTOR to overcome epidermal growth factor receptor tyrosine kinase inhibitor resistance in non-small cell lung cancer cells. PLoS One 8: e69104, 2013.

17. Meng H, Shen Y, Shen J, Zhou F, Shen S and Das UN: Effect of n-3 and n- 6 unsaturated fatty acids on prostate cancer (PC-3) and prostate epithelial (RWPE-1) cells in vitro. Lipids Health Dis 12 : 160, 2013.

18. Gatenby RA and Gillies RJ: Why do cancers have high aerobic glycolysis? Nat Rev Cancer 4: 891-899, 2004.

19. Zhan N, Li B, Xu X, Xu J and Hu S: Inhibition of FASN expression enhances radiosensitivity in human non-small cell lung cancer. Oncol Lett 15: 4578-4584, 2018

20. Ali A, Levantini E, Teo JT, Goggi J, Clohessy JG, Wu CS Chen L, Yang H, Krishnan I, Kocher O, et al: Fatty acid synthase mediates EGFR palmitoylation in EGFR mutated non-small cell lung cancer. EMBO Mol Med 10: e8313, 2018.

21. Shen M, Tsai Y, Zhu R, Keng PC, Chen Y, Chen Y and Lee SO: FASN-TGF-beta1-PD-L1 axis contributes to the development of resistance to NK cell cytotoxicity of cisplatin-resistant lung cancer cells. Biochim Biophys Acta Mol Cell Biol Lipids 1863: 313-322, 2018

22. Gouw AM, Eberlin LS, Margulis K, Sullivan DK, Toal GG, Tong L, Zare RN and Felsher DW: Oncogene KRAS activates fatty acid synthase, resulting in specific ERK and lipid signatures associated with lung adenocarcinoma. Proc Natl Acad Sci USA 114: 4300-4305, 2017.

23. Li G, Li M, Hu J, Lei R, Xiong H, Ji H, Yin H, Wei Q and Hu G: The microRNA-182-PDK4 axis regulates lung tumorigenesis by modulating pyruvate dehydrogenase and lipogenesis. Oncogene 36: 989-998, 2017.

24. Zhang C, Yu H, Ni X, Shen S and Das UN: Growth inhibitory effect of polyunsaturated fatty acids (PUFAs) on colon cancer cells via their growth inhibitory metabolites and fatty acid composition changes. PLoS One 10: e0123256, 2015.

25. Lin L, Ding Y, Wang Y, Wang Z, Yin X, Yan G, Zhang L, Yang P and Shen H: Functional lipidomics: Palmitic acid impairs hepatocellular carcinoma development by modulating membrane fluidity and glucose metabolism. Hepatology 66: 432-448, 2017.

26. Malhotra A, Redberg RF and Meier P: Saturated fat does not clog the arteries: Coronary heart disease is a chronic inflammatory condition, the risk of which can be effectively reduced from healthy lifestyle interventions. Br J Sports Med 51: 1111-1112, 2017.

27. Liu Y, Cheng Y, Li J, Wang Y and Liu Y: Epoxy stearic acid, an oxidative product derived from oleic acid, induces cytotoxicity, oxidative stress, and apoptosis in HepG2 cells. J Agric Food Chem 66: 5237-5246, 2018

28. Wongtangtintharn $\mathrm{S}, \mathrm{Oku} \mathrm{H}$, Iwasaki $\mathrm{H}$ and Toda T: Effect of branched-chain fatty acids on fatty acid biosynthesis of human breast cancer cells. J Nutr Sci Vitaminol (Tokyo) 50: 137-143, 2004.

29. Yin Y, Sui C, Meng F, Ma P and Jiang Y: The omega-3 polyunsaturated fatty acid docosahexaenoic acid inhibits proliferation and progression of non-small cell lung cancer cells through the reactive oxygen species-mediated inactivation of the PI3K/Akt pathway. Lipids Health Dis 16: 87, 2017.
30. Igal RA: Roles of stearoylcoa desaturase-1 in the regulation of cancer cell growth, survival and tumorigenesis. Cancers (Basel) 3: 2462-2477, 2011.

31. Noto A, Raffa S, De Vitis C, Roscilli G, Malpicci D, Coluccia P, Di Napoli A, Ricci A, Giovagnoli MR, Aurisicchio L, et al: Stearoyl-CoA desaturase-1 is a key factor for lung cancer-initiating cells. Cell Death Dis 4: e947, 2013.

32. Ferrannini E, Barrett EJ, Bevilacqua S and DeFronzo RA: Effect of fatty acids on glucose production and utilization in man. J Clin Invest 72: 1737-1747, 1983.

33. Nestel PJ, Straznicky N, Mellett NA, Wong G, De Souza DP, Tull DL, Barlow CK, Grima MT and Meikle PJ: Specific plasma lipid classes and phospholipid fatty acids indicative of dairy food consumption associate with insulin sensitivity. Am J Clin Nutr 99: 46-53, 2014.

34. Krachler B, Norberg M, Eriksson JW, Hallmans G, Johansson I, Vessby B, Weinehall L and Lindahl B: Fatty acid profile of the erythrocyte membrane preceding development of type 2 diabetes mellitus. Nutr Metab Cardiovasc Dis 18: 503-510, 2008.

35. Maruyama C, Yoneyama M, Suyama N, Yoshimi K, Teramoto A, Sakaki Y, Suto Y, Takahashi K, Araki R, Ishizaka Y, et al: Differences in serum phospholipid fatty acid compositions and estimated desaturase activities between Japanese men with and without metabolic syndrome. J Atheroscler Thromb 15: 306-313, 2008.

36. Magnusdottir OK, Landberg R, Gunnarsdottir I, Cloetens L, Akesson B, Landin-Olsson M, Rosqvist F, Iggman D, Schwab U, Herzig KH, et al: Plasma alkylresorcinols C17:0/C21:0 ratio, a biomarker of relative whole-grain rye intake, is associated to insulin sensitivity: A randomized study. Eur J Clin Nutr 68: 453-458, 2014.

37. Forouhi NG, Koulman A, Sharp SJ, Imamura F, Kröger J, Schulze MB, Crowe FL, Huerta JM, Guevara M, Beulens JW, et al: Differences in the prospective association between individual plasma phospholipid saturated fatty acids and incident type 2 diabetes: The EPIC-InterAct case-cohort study. Lancet Diabetes Endocrinol 2: 810-818, 2014.

38. Abdullah MM, Cyr A, Lépine MC, Labonté MÈ, Couture P, Jones PJ and Lamarche B: Recommended dairy product intake modulates circulating fatty acid profile in healthy adults: A multi-centre cross-over study. Br J Nutr 113: 435-444, 2015.

39. Finocchiaro C, Segre O, Fadda M, Monge T, Scigliano M, Schena M, Tinivella M, Tiozzo E, Catalano MG, Pugliese M, et al: Effect of n-3 fatty acids on patients with advanced lung cancer: A double-blind, placebo-controlled study. Br J Nutr 108: 327-333, 2012.

40. van der Meij BS, Langius JA, Spreeuwenberg MD, Slootmaker SM, Paul MA, Smit EF and van Leeuwen PA: Oral nutritional supplements containing n-3 polyunsaturated fatty acids affect quality of life and functional status in lung cancer patients during multimodality treatment: An RCT. Eur J Clin Nutr 66: 399-404, 2012. 